\title{
New Agreement Between EFSUMB and the United European Gastroenterology
}

EFSUMB and the United European Gastroenterology (UEG) have set up a new agreement to describe the collaboration between the two federations, in particular regarding the annual United European Gas-
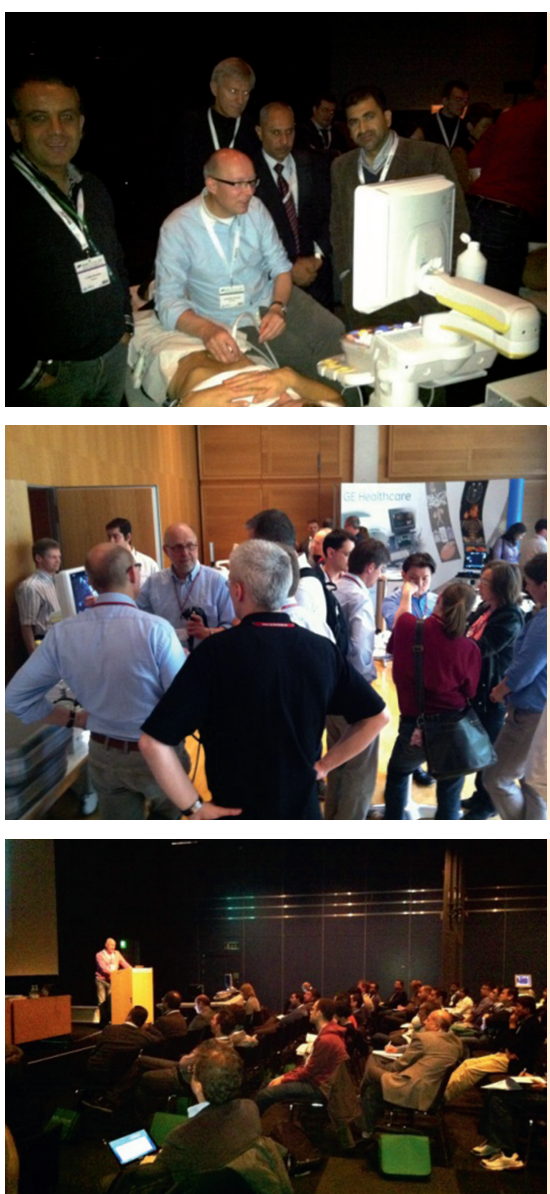

troenterology Week (UEGW). UEG acknowledges the importance of the Ultrasound Learning Centre at the UEG Week, where lecturers from EFSUMB have contributed for many years. Both EFSUMB and

The Postgraduate Course on Ultrasound - A twoday pre-congress course with lectures and handson training.

The Ultrasound Learning Centre localised within the congress area where scanners and models are available throughout the congress for hands-on training with supervision of ultrasound experts.

Three to four lunch lectures each day during the congress.
UEG wish to continue this successful cooperation. The Ultrasound Learning Centre is currently organised in three parts:

The EFSUMB Executive Bureau has appointed Prof. Dieter Nürnberg as Course Director. He is taking over the very important work Prof. Lucas Greiner has done through many years of faithful service. On behalf of EFSUMB and the European ultrasound community I will take this opportunity to extend our warmest appreciation to Prof. Lucas Greiner for the enormous efforts he has given this task to provide high level ultrasound education to a world-wide audience.

Furthermore, UEG and EFSUMB are working together to foster a closer relationship aimed at promoting the best of education in ultrasonography and gastroenterology and across the European community regarding promotion, visibility and scientific contribution.

The UEG Scientific Committee welcomes any suggestions from EFSUMB as regards talks, symposia or common interest group meetings at UEG Week and vice versa.

It is my strong wish that through this agreement with UEG, EFSUMB can increase the impact of ultrasonography in the daily work routines of gastroenterologists to improve management of patients.

Odd Helge Gilja EFSUMB Hon Secretary 